\title{
A policy-based multi-objective optimisation framework for residential distributed energy system design ${ }^{\star}$
}

\author{
Carmen Wouters $^{1}$, Eric S. Fraga ${ }^{2}$, and Adrian M. James ${ }^{1, *}$ \\ ${ }^{1}$ School of Energy and Resources, University College London (UCL), Adelaide, SA 5000, Australia \\ ${ }^{2}$ Centre for Process Systems Engineering, Department of Chemical Engineering, University College London (UCL), \\ London WC1E 7JE, UK
}

Received: 2 March 2017 / Received in final form: 6 July 2017 / Accepted: 27 July 2017

\begin{abstract}
Distributed energy systems (DES) are increasingly being introduced as solutions to alleviate conventional energy system challenges related to energy security, climate change and increasing demands. From a technological and economic perspective, distributed energy resources are already becoming viable. The question still remains as to how these technologies and practices can be "best" selected, sized and integrated within consumer areas. To aid decision-makers and enable widespread DES adoption, a strategic superstructure design framework is therefore still required that ensures balancing of multiple stakeholder interests and fits in with liberalised energy system objectives of competition, security of supply and sustainability. Such a design framework is presented in this work. An optimisation-based approach for the design of neighbourhood-based DES is developed that enables meeting their yearly electricity, heating and cooling needs by appropriately selecting, sizing and locating technologies and energy interactions. A pool of poly-generation and storage technologies is hereto considered combined with local energy sharing between participating prosumers through thermal pipeline design and microgrid operation, and, a bi-directional connection with the central distribution grid. A superstructure mixed-integer linear programming approach (MILP) is proposed to trade off three minimisation objectives in the design process: total annualised cost, annual $\mathrm{CO}_{2}$ emissions and electrical system unavailability, aligned with the three central energy system objectives. The developed model is applied on a small South Australian neighbourhood. The approach enables identifying "knee-point" neighbourhood energy system designs through Pareto trade-offs between objectives and serves to inform decision-makers about the impact of policy objectives on DES development strategies.
\end{abstract}

\section{Introduction}

Small-scale distributed generation units (DG units) could help to address conventional power system challenges such as reduction of emissions, diversification and security of supply. DG units are ideally combined into highly efficient distributed energy systems (DES) that consist of locally controlled sources and sinks, and an optional interconnection with the central grid that:

- can exploit locally available renewable energy resources;

- can optimally share locally generated energy between its participants;

- are tailored to local requirements;

- require a cost effective and efficient energy system design.

\footnotetext{
^ Paper presented at the World Renewable Energy Congress XVI,

5-9 February 2017, Murdoch University, Western Australia.

* e-mail: a.james@ucl.ac.uk
}

This paper addresses the problem of how distributed energy systems (DES), accommodated within a small residential neighbourhood and framed by location specific environment, can be designed to meet the electricity, heating and cooling demands of the residents while balancing three energy system objectives in the design process. The developed approach is based on the authors' original cost-minimisation model [1], later developed into a cost-unavailability bi-objective trade off with a weightedsum approach [2]. This paper fully completes a model that is able to optimise design while taking in account the energy trilemma of affordability (min cost), sustainability (min $\mathrm{CO}_{2}$ emissions) and security of supply (min electrical system unavailability) in a three-objective optimisation trade-off.

Multi-objective design of residential energy systems that combine the provision of electricity, heating and cooling as well as local energy sharing, is an upcoming field of research. DES design has generally been optimised 


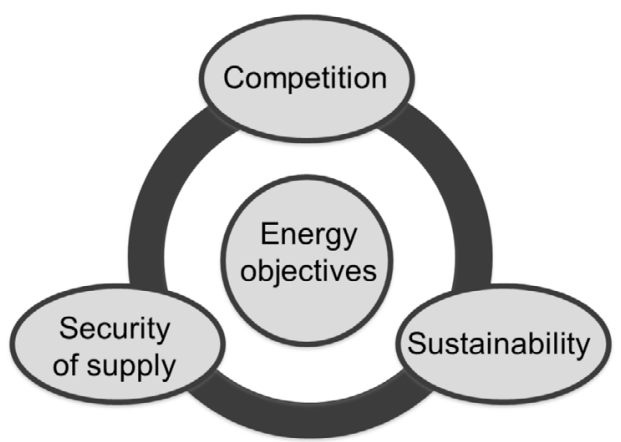

Fig. 1. Central energy system design objectives. (Adapted from [3].)

throughout literature using easily quantifiable economic/ financial, technical or environmental single objectives throughout literature. Single-objective models make up the majority of developed approaches. Bi-objective optimisation models are still under-represented and predominantly combine an economic and environmental objective [1,3-5]. Approaches for DES design with energy sharing under more than two objectives have only been researched very limitedly, for example, through a weighted-sum approach of economic, technical and environmental indices [6] or through an evolutionary approach [7]. Lastly, policy relevance was considered by [8], who developed a two-stage multi-objective technology-policy framework with economic, technical and environmental objectives for a typical commercial building in the Northeastern United States.

The objective of this paper is to fill this gap in policyrelevant multi-objective DES design by developing a policy-based optimisation framework for DES design, taking into account multiple objectives that fit in with central energy system objectives. Since system design depends on both techno-economic engineering design principles and organisational-regulatory aspects [8,9], the developed framework aims to encompass these disciplines through a multi-objective optimisation approach, which is both robust and scalable.

\section{Methodology}

Central energy systems are faced by challenges related to increasing peak demand, ageing infrastructure and climate change. Future energy system design needs to address these challenges while balancing three objectives of competition (affordability), security of supply and environmental sustainability (Fig. 1).

For DES to help alleviating central energy system challenges, these three objectives need to be traded off in the design process.

A decision-making framework, formulated as a mixedinteger linear program (MILP) [10], to optimise the energy system design of a small residential (neighbourhood) DES is presented trading off three conflicting objectives in the design process. The characteristics of the framework are detailed in previous work of the authors $[1,2]$ and summarised below:

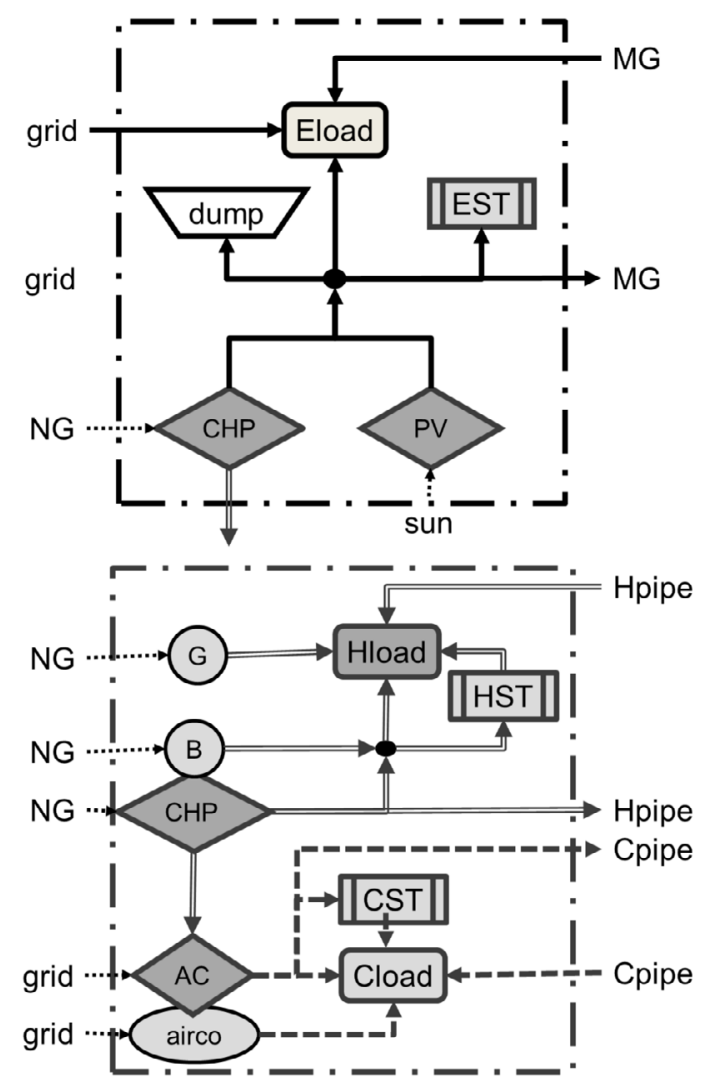

Fig. 2. Black-box diagram of energy supply options. AC, absorption chiller; B, boiler; CHP, micro combined heat and power unit; Cpipe, cooling pipeline; G, gas heater; $\mathrm{MG}$, microgrid electricity sharing; Hpipe, heating pipe; PV, photovoltaic unit; Dump, dump load; CST, cold storage unit; EST, electrical storage unit; HST, hot storage unit; NG, natural gas; Cload, cooling load; Eload, electrical load; Hload, heating load [3].

- energy integrated approach where a microgrid structure allows for sharing of locally produced electricity and residential tri-generation, combined with an optimised thermal pipeline network, supports a fully integrated thermal supply [4];

- superstructure methodology where each component is treated as a black-box characterised by a set of operational and design parameters, allowing for a model building without the necessity for detailed thermodynamic and electrical analysis [11] (Fig. 2);

- selection, siting and sizing of units from a generic pool of small-scale, mini and micro units $<30 \mathrm{~kW}$ which are commercially available and able to exploit local resources (Tab. 1 and [12]);

- typical day $(24 \mathrm{~h})$ per season over yearly planning horizon.

The three energy system objectives are translated into three design objectives, representing the minimisation of: - total annualised energy costs of the neighbourhood as a whole $\left(C^{\mathrm{TOT}, \mathrm{S}}\left[\mathrm{kAUD} \mathrm{y}^{-1}\right]\right)$, combining annual technology costs (investment, fuel and operation and maintenance), cost of importing central grid electricity, and potential cost offsetting through residential DG electric- 
Table 1. Classification of DG units in the National Electricity Market of Australia. (Adapted from the Australian Energy Market Operator [17].)

\begin{tabular}{lll}
\hline Classification & Technical definition & Typical installation \\
\hline Micro & $\leq 2 \mathrm{~kW}$ and connect to LV network & Roof top solar PV \\
Mini & $2-10 \mathrm{~kW}(1 \phi)$ or $30 \mathrm{~kW}(3 \phi)$ & Fuel cells; combined heat and power systems \\
Small & $10 \mathrm{~kW}(1 \phi)$ or $30 \mathrm{~kW}(3 \phi)$ to $1 \mathrm{MW}$ & Biomass, small hydro \\
Medium & $1-5 \mathrm{MW}$ & Biomass, hydro, local wind generating units \\
Large & $\geq 5 \mathrm{MW}$ & Co-generation, hydro, solar thermal, wind \\
\hline
\end{tabular}

ity export at feed-in tariffs (Eq. (1)):

$$
C^{\mathrm{TOT}, \mathrm{S}}=C^{\mathrm{INV}}+C^{\mathrm{OM}}+C^{\mathrm{FUEL}}+C^{\mathrm{GRID}}-C^{\mathrm{SAL}},
$$

where $C^{\mathrm{NNV}}$, yearly neighbourhood technology investment cost; $C^{\mathrm{OM}}$, yearly neighbourhood operation and maintenance costs; $C^{\text {FUEL }}$, yearly neighbourhood fuel costs; $C^{\text {GRID }}$, yearly neighbourhood grid electricity import costs; $C^{\text {SAL }}$, yearly neighbourhood electricity export income;

- average house electrical system unavailability in the neighbourhood ( $\left.\mathrm{UA}^{\mathrm{TOT}, \mathrm{S}}\left[\log _{10}\right]\right)$, which is the sum of the electrical system unavailability of individual houses divided by the total number of neighbourhood houses (Eq. (2)), with the house electrical system unavailability modelled as an OR-gate of mutually exclusive potential configurations [13] (Eq. (3)):

$$
\mathrm{UA}^{\mathrm{TOT}, \mathrm{S}}=\sum_{i} \mathrm{UA}_{i} / n_{\mathrm{h}},
$$

with

$$
\mathrm{UA}_{i}=\sum_{\mathrm{con}} B_{\mathrm{con}, i} \cdot \log 10\left(\mathrm{ua}_{\mathrm{con}}\right)
$$

where $\mathrm{UA}_{i}$, house electrical system unavailability; $n_{\mathrm{h}}$, number of neighbourhood houses; $B_{\mathrm{con}, i}$, binary decision variable that decides on the installation of the electrical system configuration con in house $i$ (several pre-defined combinations of technologies in each house make up the different configurations); $\mathrm{ua}_{\mathrm{con}}$, unavailability of configuration con. Note that a logarithmic transformation of obtained unavailability inputs is employed to bring the different objectives within similar range and to indirectly measure unavailability as availability through a number of "nines" [14]; and

- annual neighbourhood $\mathrm{CO}_{2}$ emissions $\left(\mathrm{EM}^{\mathrm{TOT}, \mathrm{S}}\left[\right.\right.$ tonCO $\mathrm{CO}_{2}$ $\left.\mathrm{y}^{-1}\right]$ ), combining the carbon emissions related to the yearly imported grid electricity as well as natural gas consumption by the dispatchable units in the neighbourhood (Eq. (4)):

$$
\begin{aligned}
\mathrm{EM}^{\mathrm{TOT}, \mathrm{S}} & =\mathrm{CI}_{\text {elc }} \sum_{i} \mathrm{PE}_{i}^{\mathrm{GRID}} \\
& +\mathrm{CI}_{\text {gas }} \sum_{i, \text { tech }}^{\mathrm{PH}_{i, \text { techTH }}^{\mathrm{TOT}} / n_{\text {techTH }}^{\text {th }}} \\
& +\mathrm{CI}_{\text {gas }} \sum_{i} \mathrm{PE}_{i, \mathrm{CHP}}^{\mathrm{TOT}} / n^{\text {elc }} \mathrm{CHP},
\end{aligned}
$$

where $\mathrm{CI}_{\text {elc }}$, carbon intensity grid $\left[\mathrm{kgCO}_{2} \mathrm{kWh}^{-1}\right]$; $\mathrm{CI}_{\text {gas }}$, carbon intensity natural gas $\left[\mathrm{kgCO}_{2} \mathrm{kWh}^{-1}\right] ; \mathrm{PE}_{i}^{\mathrm{GRID}}$, yearly electricity grid import house $i\left[\mathrm{kWhy}^{-1}\right]$;
$\mathrm{PH}_{i \text { techTH }}^{\mathrm{TOT}}$, yearly heat generated by technology techTH in house $i\left[\mathrm{kWhy}^{-1}\right] ; n_{\text {tech }}^{\text {th }}$, thermal efficiency technology techTH; $\mathrm{PE}_{i, \mathrm{CHP}}^{\mathrm{TOT}}$, yearly electricity generation by CHP in house $i\left[\mathrm{kWhy}^{-1}\right] ; n_{\mathrm{CHP}}^{\text {elc }}$, CHP electrical efficiency.

Three objectives are then combined into a weighted sum [5] (Eq. (5)).

$$
\min _{x, y, z}\left[\lambda_{\mathrm{c}} C^{\mathrm{TOT}, \mathrm{S}}+\lambda_{\mathrm{a}} \mathrm{UA}^{\mathrm{TOT}, \mathrm{S}}+\lambda_{\mathrm{e}} \mathrm{EM}^{\mathrm{TOT}, \mathrm{S}}\right],
$$

with $x$ technology options, $y$ their capacities and $z$ neighbourhood locations, subject to local energy demands and input parameters.

$\lambda_{i}$ are the weights of the three objectives $i$ in the combined objective function, with $\Sigma_{i} \lambda_{i}=1$ and $\lambda_{i} \in[0,1]$.

The objective function is solved through a deterministic GAMS optimisation [15] with the CPLEX solver v12.4.0.1 [16], and an OPTCR of 0\%. Full details of the model implementation can be found in previous work of the authors regarding the single-objective cost minimisation model [1] and the multi-objective cost-unavailability minimisation model [2].

\section{Results}

\subsection{Case study}

A fictitious 5-house Adelaide-based residential neighbourhood is analysed based on a three objective energy system design trade-off by varying the different objective weights. Location-specific inputs for a typical day in each season are used: climatological data, technical specifications of units, costs, tariffs, regulations and spatial distributions of hourly average energy demands for a typical day in each season $[\mathrm{kW}]$.

Total neighbourhood installed unit capacities of selected lambda values $(\lambda)$ for the three trade-offs are summarised in Table 2. Cost $\left(C^{\mathrm{TOT}, \mathrm{S}}\left[\mathrm{kAUDy}^{-1}\right]\right), \mathrm{CO}_{2}$ emissions $\left(\mathrm{EM}^{\mathrm{S}}\left[\mathrm{tonCO}_{2} \mathrm{y}^{-1}\right]\right)$ and unavailability $\left(\mathrm{UA}^{\mathrm{TOT}, \mathrm{S}}\right)$ is measured a $\log _{10}$ the number of nines of availability (i.e. 3 nines $=99.9 \%$ availability).

Figure 3 illustrates selected design changes and Table 2 summarises key results of the different designs. In between the illustrated designs, the transition is more gradual with an increasing number of microgrid-available CHP units and batteries. Available PV units are installed in all houses until $\lambda_{\mathrm{c}}=0.230$, from this point on batteries start to appear. From here the trade-off is more gradual as both PV and CHP are available to charge the increasing storage 
Table 2. Objective values, total neighbourhood installed unit capacities [kW or $\mathrm{kWh}(\mathrm{EST})]$, and microgrid existence (MG) for selected $\lambda$-values for each bi-objective trade-off. A total airco capacity of $11.2 \mathrm{~kW}$ is installed in all cases.

\begin{tabular}{|c|c|c|c|c|c|c|c|c|c|}
\hline & $C^{\mathrm{TOT}, \mathrm{S}}$ & $\mathrm{EM}^{\mathrm{S}}$ & $\mathrm{UA}^{\mathrm{TOT}, \mathrm{S}}$ & PV & $\mathrm{CHP}$ & $B$ & $\mathrm{EST}$ & HST & MG \\
\hline \multicolumn{10}{|c|}{ Unavailability-cost $\left(\lambda_{\mathrm{e}}=0\right)$} \\
\hline$\lambda_{\mathrm{c}}=1.000$ & 22.264 & 30.194 & -3.611 & 10.5 & 2.1 & 26.0 & 0 & 5.4 & $\checkmark$ \\
\hline$\lambda_{\mathrm{c}}=0.4100$ & 23.866 & 29.754 & -4.729 & 10.5 & 8.0 & 25.0 & 0 & 4.9 & $\checkmark$ \\
\hline$\lambda_{\mathrm{c}}=0.230$ & 33.473 & 32.729 & -8.829 & 10 & 34.1 & 7.6 & 2.1 & 20.4 & $\checkmark$ \\
\hline$\lambda_{\mathrm{c}}=0.159$ & 39.753 & 33.017 & -10.248 & 13.5 & 45.4 & 0 & 13.5 & 11.1 & $\checkmark$ \\
\hline$\lambda_{\mathrm{c}}=0.060$ & 43.000 & 31.935 & -10.684 & 25.0 & 52.2 & 0 & 13.5 & 5.5 & $\checkmark$ \\
\hline \multicolumn{10}{|c|}{ Emissions-cost $\left(\lambda_{\mathrm{a}}=0\right)$} \\
\hline$\lambda_{\mathrm{c}}=1.0000$ & 22.264 & 30.194 & -3.611 & 10.5 & 2.1 & 26.0 & 0 & 5.4 & $\checkmark$ \\
\hline$\lambda_{\mathrm{c}}=0.9000$ & 22.266 & 30.145 & -3.589 & 10.7 & 2.1 & 27.4 & 0 & 2.1 & $\checkmark$ \\
\hline$\lambda_{\mathrm{c}}=0.3190$ & 26.325 & 26.051 & -3.698 & 22.7 & 1.9 & 28.3 & 19.9 & 3.0 & $\checkmark$ \\
\hline$\lambda_{\mathrm{c}}=0.0180$ & 32.944 & 22.957 & -3.440 & 25.0 & 0 & 33.6 & 57.4 & 0.6 & - \\
\hline$\lambda_{\mathrm{c}}=0.1954$ & 35.000 & 22.454 & -0.219 & 25.0 & 0 & 33.9 & 68.4 & 0 & - \\
\hline \multicolumn{10}{|c|}{ Unavailability-emissions $\left(\lambda_{\mathrm{c}}=0\right)$} \\
\hline$\lambda_{\mathrm{e}}=0.995$ & 42.422 & 22.454 & -3.440 & 46.5 & 0 & 175 & 61.9 & 250 & $\checkmark$ \\
\hline$\lambda_{\mathrm{e}}=0.600$ & 49.986 & 23.560 & -5.117 & 50.3 & 20 & 140 & 77.1 & 250 & $\checkmark$ \\
\hline$\lambda_{\mathrm{e}}=0.300$ & 73.474 & 29.363 & -10.684 & 47.7 & 100 & 0 & 69.6 & 250 & $\checkmark$ \\
\hline
\end{tabular}

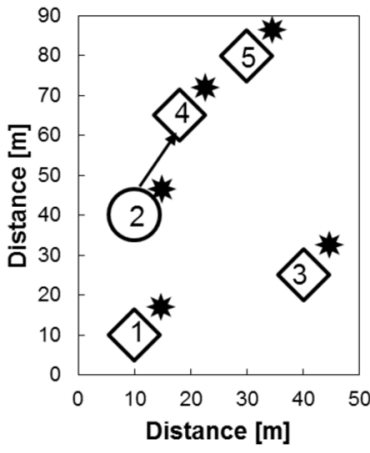

$\lambda_{c}=1.000$

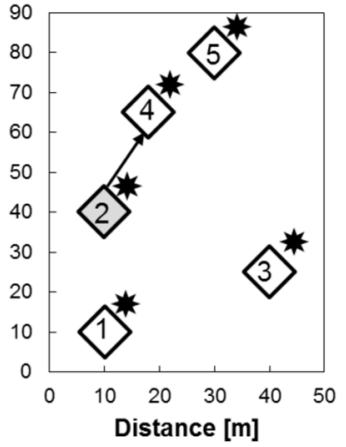

$\lambda_{\mathrm{c}}=0.410$

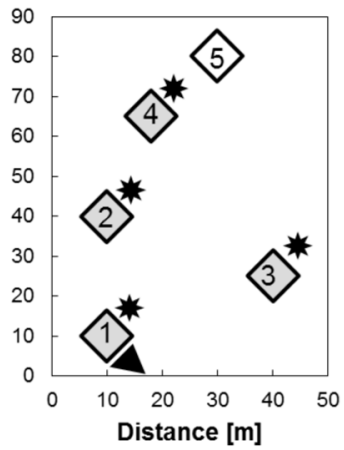

$\lambda_{c}=0.230$

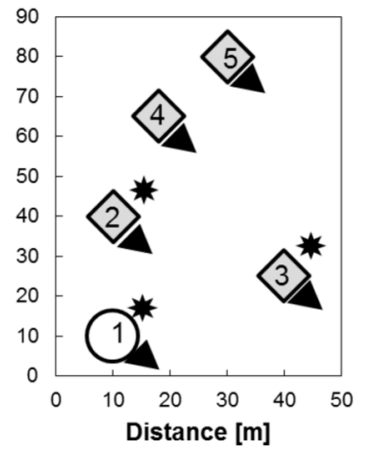

$\lambda_{\mathrm{c}}=0.159$

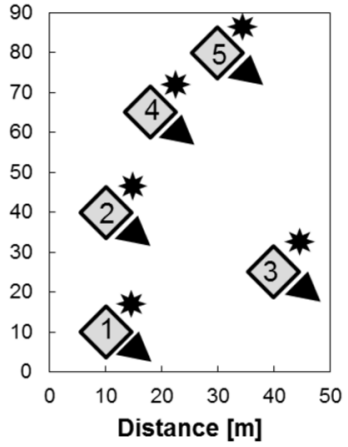

$\lambda_{\mathrm{c}}=0.060$

Fig. 3. Major design changes for unavailability-cost trade-off for several values of $\lambda_{\mathrm{c}}$ and $\lambda_{\mathrm{a}}$, with $\lambda_{\mathrm{e}}=0$. White diamonds, boiler and airco; white circle, available CHP for house and airco; grey diamond, available CHP for MG and airco; sun, PV; triangle, battery; black arrow, heating pipe; $\mathrm{H}$, hot storage. All houses have a grid connection [3].

capacity provided by the batteries. Discrete jumps between Pareto points occur due to the discrete relationship between unavailability and unit capacity, although this relationship is component dependent and can be changed in the model [2]. A 31\% drop in unavailability, i.e. a 1 nine increases availability, and a small cost increase of $7.2 \%$ occurs between the first and second point $\left(\lambda_{\mathrm{c}}=1.000\right.$ and $\lambda_{\mathrm{c}}=0.410$ respectively). The only installed neighbourhood CHP unit capacity increases here as it now becomes available for export into the microgrid as well as meeting the demand from its accommodating house. The latter design represents the highest availability increase for the lowest additional cost (largest gradient).
Figure 4 illustrates the trade-off of the three objectives in terms of number of nines in availability (bubble size) for different combinations of cost and emissions, leading to discrete solutions. The area defined by the dashed line represents an acceptable availability level within the 4-6 nines range. This exhibits the maximum increase in gradient between the iso-availability fronts representing the highest availability increase for the lowest additional emissions and cost. Looking in more detail the best 4-nine design gives an availability improvement of 1 nine with a relatively small cost increase of $9 \%$ from the optimal cost. The only design change compared to cost-optimal design, is an increase of the installed CHP capacity in house 2 as it 


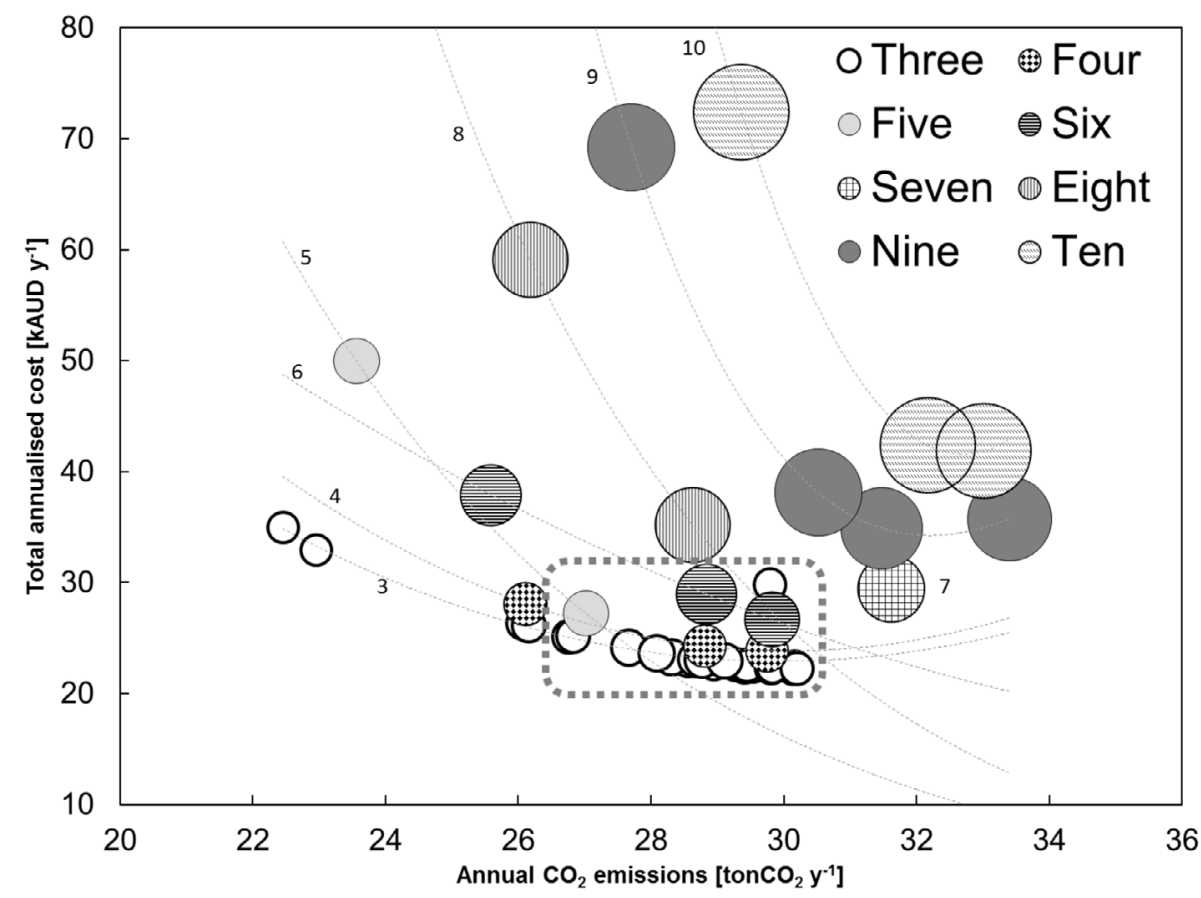

Fig. 4. Bubble chart of three objective trade-off. Cost and emissions are indicated on axes and the size of the bubbles indicates the number of nines of the average house electrical system availability. Dotted lines, iso-availability curves and are numbered with the number of nines of availability from 3 to 10 [3].

becomes available to the wider microgrid. The lowest cost 5 -nine availability point improves availability by 2 nines compared to the cost-optimal solution; cost increases by $22 \%$ and emission reduces by $11 \%$. The "best" 5 -nine design has one microgrid-available CHP in house 1 , two hot pipelines (1-4 and 4-5) and batteries implemented in 4 houses. The 5 -nine point is, however, relatively more expensive to increase system availability than the 6-nine right-most point. In this 6-nine point, availability is increased by 2 nines compared to cost-optimal, for a cost increase of only $20 \%$. Emissions are here, however, only reduced by $1 \%$. This cheapest 6 -nine design has two microgrid-available CHP units in houses 1 and 2 and no batteries or pipelines installed. Electricity sharing and an available PV unit in each house are adopted in each design. This description shows that a trade-off between three objectives does not provide a single straightforward "kneepoint" design. The framework, however, does allow the decision maker to experiment with relative importance of objectives/stakeholder interests and hence determine the most suitable neighbourhood system design.

It should be noted that as a deterministic modelling approach is employed, parameter uncertainty can affect the final results obtained. In use as a design tool it is therefore pragmatic to perform a sensitivity analysis around model component parameters where uncertainty exists.

\section{Conclusions}

An MILP approach has been presented for the superstructure, energy integrated design of residential distributed energy systems while trading off three objectives in the design process through a weighted sum. The three objectives are aligned with the central energy system objectives of affordability, sustainability and security of supply, minimising total annualised cost. A South Australian case-study was analysed to assess the effect of objective trade-offs on local energy system design, leading to the identification of subjective optimal structures. In conclusion we have shown that the availability of a multi-objective design framework, as proposed here, can be an invaluable aid to decision makers in developing energy systems policies for residential use.

\section{References}

1. C. Wouters, E.S. Fraga, A.M. James, An energy integrated, multi-microgrid, MILP (mixed-integer linear programming) approach for residential distributed energy system planning a South Australian case-study, Energy (2015), doi:10.1016/j. energy.2015.03.051

2. C. Wouters, E.S. Fraga, A.M. James, A multi-objective framework for cost-unavailability optimisation of residential distributed energy system design, Sustain. Energy Grids Netw. (2017), doi:10.1016/j.segan.2017.01.002

3. C.M. Wouters, Optimal design and regulation of residential distributed energy systems, Ph.D. thesis, University College London, 2016

4. A.N. Ünal, S. Ercan, G. Kayakutlu, Optimisation studies on tri-generation: a review, Int. J. Energy Res. 39, 1311 (2015)

5. A. Alarcon-Rodriguez, G. Ault, S. Galloway, Multi-objective planning of distributed energy resources: a review of the stateof-the-art, Renew. Sustain. Energy Rev. 14, 1353 (2010)

6. J. Keirstead, N. Samsatli, N. Shah, C. Weber, The impact of CHP (combined heat and power) planning restrictions on the efficiency of urban energy systems, Energy 41, 93 (2010) 
7. S. Fazlollahi, G. Becker, A. Ashouri, F. Maréchal, Multiobjective, multi-period optimisation of district energy systems: IV. A case study, Energy 84, 365 (2015)

8. S. Mallikarjun, H.F. Lewis, Energy technology allocation for distributed energy resources: a strategic technology-policy framework, Energy 72, 783 (2014)

9. S. Kelly, M. Pollitt, An assessment of the present and future opportunities for combined heat and power with district heating (CHP-DH) in the United Kingdom, Energy Policy 38, 6936 (2010)

10. C.A. Floudas, Nonlinear and Mixed-Integer Optimization: Fundamentals and Applications (Oxford University Press, United Kingdom, 1995), ISBN: 0-19-510056-5

11. G. Chicco, P. Mancarella, Distributed multi-generation: a comprehensive view, Renew. Sustain. Energy Rev. 13, 535 (2009)

12. S.M.C. Ang, D.J.L. Brett, I. Staffell, A.D. Hawkes, E.S. Fraga, N.J. Samsatli, N.P. Brandon, Design of fuel-cell micro-cogeneration systems through modeling and optimization, Wiley Interdiscip. Rev.: Energy Environ. 1, 181 (2012)
13. A. Villemeur, Reliability, Availability, Maintainability, and Safety Assessment: Assessment, Hardware, Software, and Human Factors (John Wiley and Sons, United Kingdom, 1992), Vol. 2, ISBN: 0-471-93048-2

14. EventHelix, Reliability and Availability Basics (2014), Available from http://www.eventhelix.com/realtimeman tra/faulthandling/reliability_availability_basics.htm\#. VFxoRme7SkN (last consulted on: $2016 / \overline{2} 4 / 05$ )

15. GAMS Development Corporation, Genetic Algebraic Modeling System, December (2016), Available from http://www. gams.com/help/topic/gams.doc/userguides/mccarl/mccarl gamsuserguide.pdf (last consulted on: 2016/04/19)

16. IBM, IBM ILOG CPLEX Optimizer Version 12.1 User's Guide (2009), Available from http://www.ampl.com/BOOK LETS/amplcplex121userguide.pdf (last consulted on: 2016/ 04/05)

17. Australian Energy Market Operator (AEMO), Fact Sheet: Distributed Generation (2012), Available from http://www. aemc.gov.au/getattachment/9aac3077-50e9-41a6-b_609bc30a00182/Distributed-generation.aspx (last consulted on: $2016 / 14 / 04)$

Cite this article as: Carmen Wouters, Eric S. Fraga, Adrian M. James, A policy-based multi-objective optimisation framework for residential distributed energy system design, Renew. Energy Environ. Sustain. 2, 5 (2017) 